Original Research Paper

\title{
The Phenomenon of Nonzero Norm of Long-Term Changes in the Total Water Supply in River Basins
}

\author{
Viktor V. Kovalenko and Ekaterina V. Gaidukova \\ Russian State Hydrometeorological University (RSHU), Saint-Petersburg, Russia
}

\section{Article history}

Received: 14-04-2014

Revised: 25-06-2014

Accepted: 05-05-2015

Corresponding Author:

Ekaterina V. Gaidukova

Russian State

Hydrometeorological University

(RSHU), Saint-Petersburg, Russia

Email: oderiut@mail.ru

\begin{abstract}
In hydrology, the norm of changes in water supply is considered to be equal to zero, under long-term averaging. This assumption allows for calculating and mapping the long-term evaporation rates linked by the water balance with maps of precipitation and river runoff. The phenomenon of nonzero norm of change of the total water supply is provided using the effect of detection in stochastic systems. Was discovered a previously unknown phenomenon of detection of long-term changes in water supply in soil of river basins, namely, that under nonzero interaction intensity of inflow (outflow) of moisture into a watershed and saturation (emptying) of soil, a non-zero value of the average annual values of water supply changes occurs, due to the systematic shift of the average value with respect to the mode of probability density distribution of water supplies. One of the obvious applications of the discovered phenomenon is the adjustment of maps of the average long term evaporation in the areas, where the norm of water supply change is significantly different from zero.
\end{abstract}

Keywords: Total Change Water Supplies, Norm, Water Balance

\section{Introduction}

The annual water balance in closed river drainages, under excluded azonal factors of discharge formation within their areas, is given by an Equation 1 (HP, 1981; Hosseini et al., 2011):

$X=Q+E \pm \Delta U$

Where:

$X=$ Precipitation

$Q=$ Runoff

$E=$ Evaporation

$\Delta U=$ Change in the total water supply in the river basin

In hydrology, the norm of changes in water supply $M[\Delta U]$ is considered to be equal to zero, under longterm averaging. This assumption allows for calculating and mapping the long-term evaporation rates linked by the water balance with maps of precipitation and river runoff (HP, 1981). The $E$ maps, both for Russia (Doganovsky and Orlov, 2011) and for the entire Earth (AMVB, 1974) are built on this basis.

\section{Materials and Methods}

In the papers (Kovalenko, 2012; Kovalenko and Gaidukova, 2011) was demonstrated that in the temperate zone, the fractal dimension of the annual longterm runoff series often lies within the range of 2-3, i.e., it is formed with participation of all three phase variables included in the right part of the formula (1) and the model of evolution of probability density $p(Q, E, \Delta U)$ does not necessarily imply that $M[\Delta U]=0$. This can be shown on the example of a stochastic equation for only one of the phase variables $\Delta U$ Equation 2:

$d(\Delta U)=\left\{\left[-\left(\mathrm{M}[c]+c^{\prime}\right) \operatorname{sgn}(\Delta U)+\mathrm{M}[N]+N^{\prime}\right] / \tau_{\Delta U}\right\} d t$

where, $N=X-Q-E ; c$ is a parameter, which characterizes the saturation rate (or water loss) of the river basin; $\tau_{\Delta U}$ - the relaxation rate of the basin capacity (Rahnama and Barani, 2005); $\operatorname{sgn}(\Delta U)$ - the sign function; $M[N], M[c]$ - expectations; $N^{\prime}$ and $c^{\prime}$ white noise with $G_{c}, G_{N}$, intensities and interrelated intensity $G_{c^{\prime} N}$, (henceforth we assume $\tau_{\Delta U}=1$ without sacrificing the generality of conclusions). 
The equation of similar (by structure) type describes a relay servo system that was studied comprehensively and for different versions by Academician V.S. Pugachev and his research fellows (Astapov and Medvedev, 1982). Based on their results, we will demonstrate the possibility of nonzero value for longterm averaged $\Delta U$. Let $M[N]=0$, against the non-zero noise intensity $\left(G_{N^{\prime}} \neq 0, G_{c^{\prime}} \neq 0, G_{c^{\prime} N^{\prime}} \neq 0\right)$.

By performing a standard transition procedure from a stochastic differential equation (in our case, (2)) to the statistically equivalent Fokker-Planck-Kolmogorov equation, we obtain the stationary probability density expression Equation 3:

$$
p(\Delta U)=k \exp \left\{-\frac{2 \mathrm{M}[c]|\Delta U|}{G_{c^{\prime}}-2 G_{c^{\prime} N} \operatorname{sgn} \Delta U+G_{N^{\prime}}}+\frac{G_{c^{\prime} N^{\prime}} \operatorname{sgn} \Delta U}{G_{c^{\prime}}+G_{N^{\prime}}}\right\}
$$

where, $k$ is a normalizing factor per unit of the integral of probability density.

If $G_{c^{\prime} N},=0$, the $p(\Delta U)$ distribution is symmetric. When $G_{c^{\prime} N^{\prime}} \neq 0$, it becomes skewed; the sign of asymmetry depends on positive or negative correlation of additive $\left(N^{\prime}\right)$ and multiplicative $\left(c^{\prime}\right)$ noises. The emergence of $M[\Delta U]_{2} \neq 0$ at zero expectation of the input $M[N]$ effect (but with an interaction of «external» $N^{\prime}$ and «internal» $c^{\prime}$ noises) is called the effect of detection (Fig. 1).

To provide the empirical validation of this effect, we apply the balance models. A well-known method (HP, 1981) allows for evaluating the statistical significance of the residual members in balance equations $\sum_{i=1}^{n} x_{i}=0$. If all members of the equation $x_{i}$ are taken into account (in the initial view of a researcher) but a residual term $\varepsilon_{0}$ appears, the error $\delta_{0}=\sqrt{\sum_{i=1}^{n} \delta_{i}^{2}}$ (here, $\delta_{I}$ is the error of the $i$-th member of the sum) must be calculated. If it does not exceed the value of residual, the latter is considered to be «serious» and its physical origin should be discussed. Under the normal law of errors: if $\left|\varepsilon_{0}\right|>\delta_{0}$, then $\varepsilon_{0}$ has $68.3 \%$ confidence, if $\left|\varepsilon_{0}\right|>2 \delta_{0}-95.4 \%$ and if $\left|\varepsilon_{0}\right|>3 \delta_{0}-99.7 \%$ (zones with statistically significant $\varepsilon_{0}$ values corresponding to $M[\Delta U]$ are presented in the map below).

In our case, the role of such «residual» member is played by a normal value of $\pm \Delta U=X-Q-E$. Hydrologists agree on this form of equation for the annual period (AL-Khlaifat, 2008). For long-term norms, it is considered (theoretically) that $M[\Delta U]=0$. To verify (or deny) this suggestion, evaporation must be evaluated independently of $X$ and $Q$. The standard guideline for drafting water balances (HP, 1981) provides a comparative assessment of basic methods for determining land evaporation and states that in relying on mass meteorological observations, semiempirical calculation methods are preferred, in particular, the widespread (HP, 1981) method of Konstantinov (1968). Following its recommendations (Konstantinov, 1968), time series for annual evaporation can be generated, by temperature $T$ and air humidity $e$ measured at the existing stations of hydrometeorological network. The practical use of these recommendations is based on the nomogram (Konstantinov, 1968) presented in coordinates $E=f(T$, $e$ ). Before we discuss the results of calculations, note that the change in water supply is often interpreted as its variations in $1-\mathrm{m}$ deep soil layer of the aeration zone, which is important in agricultural meteorology. In our case, the «residual term» characterizes the total change in water reserves in the basin (mainly in soils but not exclusively).

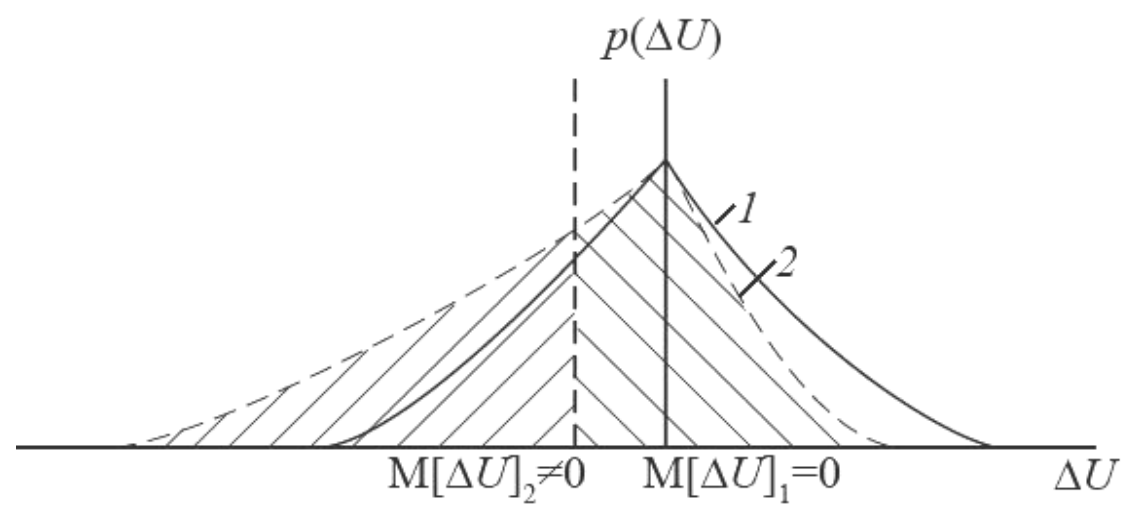

Fig. 1. The effect of detection at non-zero correlation of «external» $\left(N^{\prime}\right)$ and «internal» $\left(c^{\prime}\right)$ noises: $1-$ at $G_{c^{\prime} N^{\prime}}=0 ; 2-$ at $G_{c^{\prime} N^{\prime}} \neq 0$ 


\section{Results}

Using this methodology, the $M[\Delta U]$ values were defined for 418 global river basins (252-in Russia), where the range of $T$ and $e$ changes remained within the valid limits of Konstantinov's nomogram (zones with the extreme values located in the North of Eastern Siberia, in Africa, Latin America, Southwest Asia and Australia were excluded from consideration). Information on hydrometeorological elements was retrieved from the Internet-resources (http://www.esrl.noaa.gov/psd/data.html;

http://www.rivdis.sr.unh.edu). We considered the watersheds of large rivers with a zonal pattern of formation of the long-term runoff.

Figure 2 presents a map of distribution of $\pm M[\Delta U]$ values corresponding to the confidence level of $68.3 \%$, i.e., when $|M[\Delta U]|>\delta_{0}$, under the error values of the norms of the water balance equation components, is 1.5 times greater than those accepted in hydrology: Precipitation $7.5 \%$, runoff $-7.5 \%$, evaporation - 22.5. At high confidence probabilities $(95.4 \% ; 99.7 \%)$ maps become more mottled (patchy), because of the disappeared (become statistically insignificant) areas, where $|M[\Delta U]|$ $<2 \delta_{0}$ (at 95.4\%) and $|M[\Delta U]|<3 \delta_{0}(99.7 \%)$.

Figure 3 represents a typical example of chronological course of hydrometeorological elements and their histograms.

\section{Discussion}

White-colored areas on the map (Fig. 2) refer either to uncalculated (for the above mentioned reasons) areas or to those, where $M[\Delta U]$ values can be considered (at a certain level of statistical significance) as almost zero (about $50 \%$ of the territory). For instance, Russia is characterized by the predominance of negative norms in the European part (with the Western moisture transport) and in the Eastern zone of the Pacific influence. The $|M[\Delta U]|$ numerical values are generally less than the long-term norms of other components in the water balance equation of river drainages but allow for mapping and identification of geographical patterns, as reflected partly in Fig. 2.

Analysis of similar figures, as in Fig. 3, drawn for 252 basins of Russia provides certain generalizations: (1) Histograms of water supply change can be bimodal (the norm is always single); (2) evaporation histograms often have a negative skew (as compared with consumption histograms); (3) approximately 25$30 \%$ of graphs of water supply change are placed entirely either in the negative or in the positive areas.

The first case is due to hysteresis effects and is partly addressed in the study (Kovalenko, 2009). The negative skew in evaporation series is explained by the same detection effect; however this is not yet fully studied in physiography (the same as with the runoff series). The most intriguing situation is presented by the third generalization. Given that the value of $\pm \Delta U$ is the time derivative of the water supply volume, location of a chronological graph $\Delta U(t)$ in the same area, e.g., in the negative, does not indicate the process of water supply exhaustion. According to the differential calculus, the derivative of a function with zero average value does not necessarily have an average of zero.

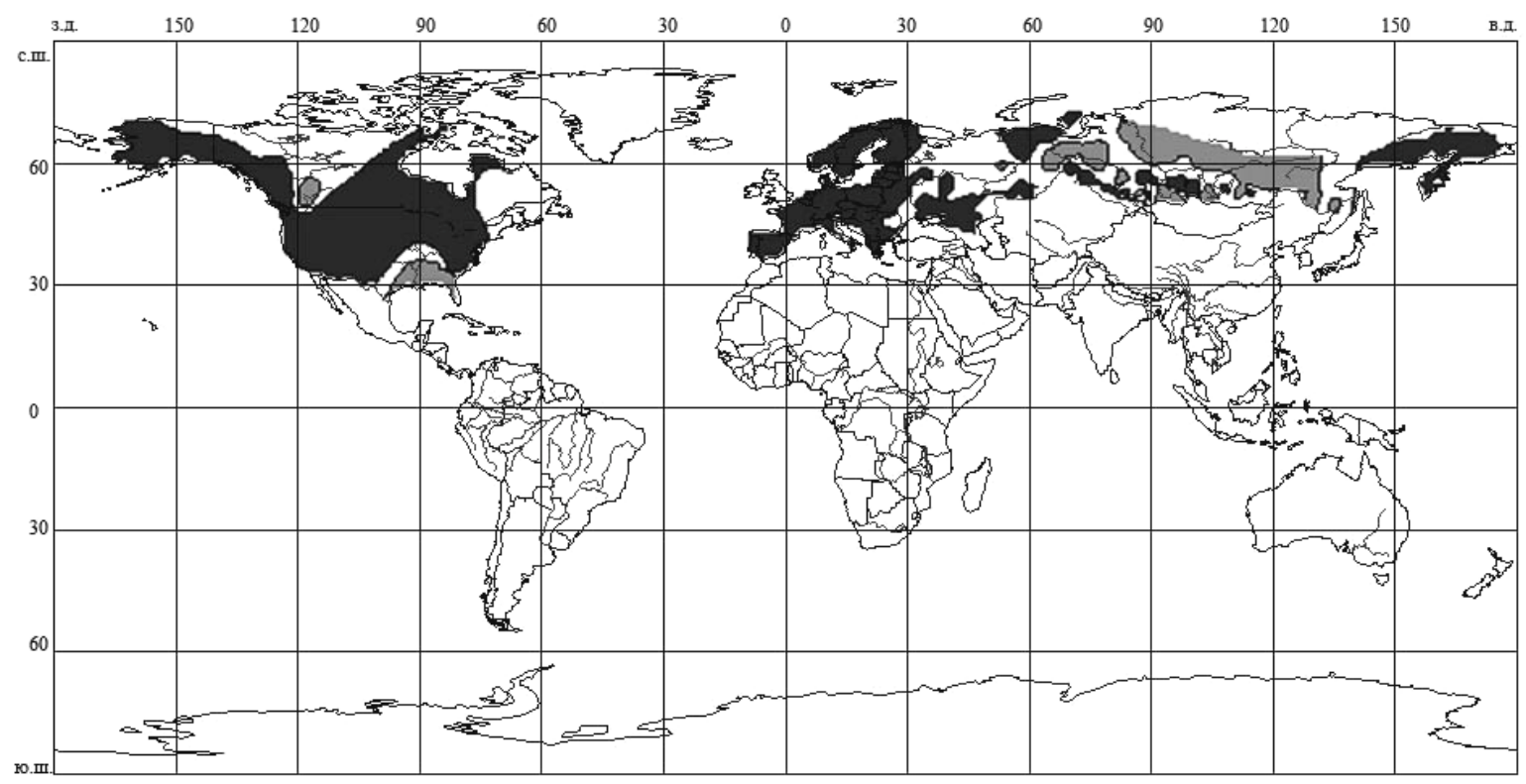

Fig. 2. Distribution of statistically significant values of long-term norm of change of the total water supply in river basins (black color - for $M[\Delta U]<0$, grey color - for $M[\Delta U]>0$ ) 

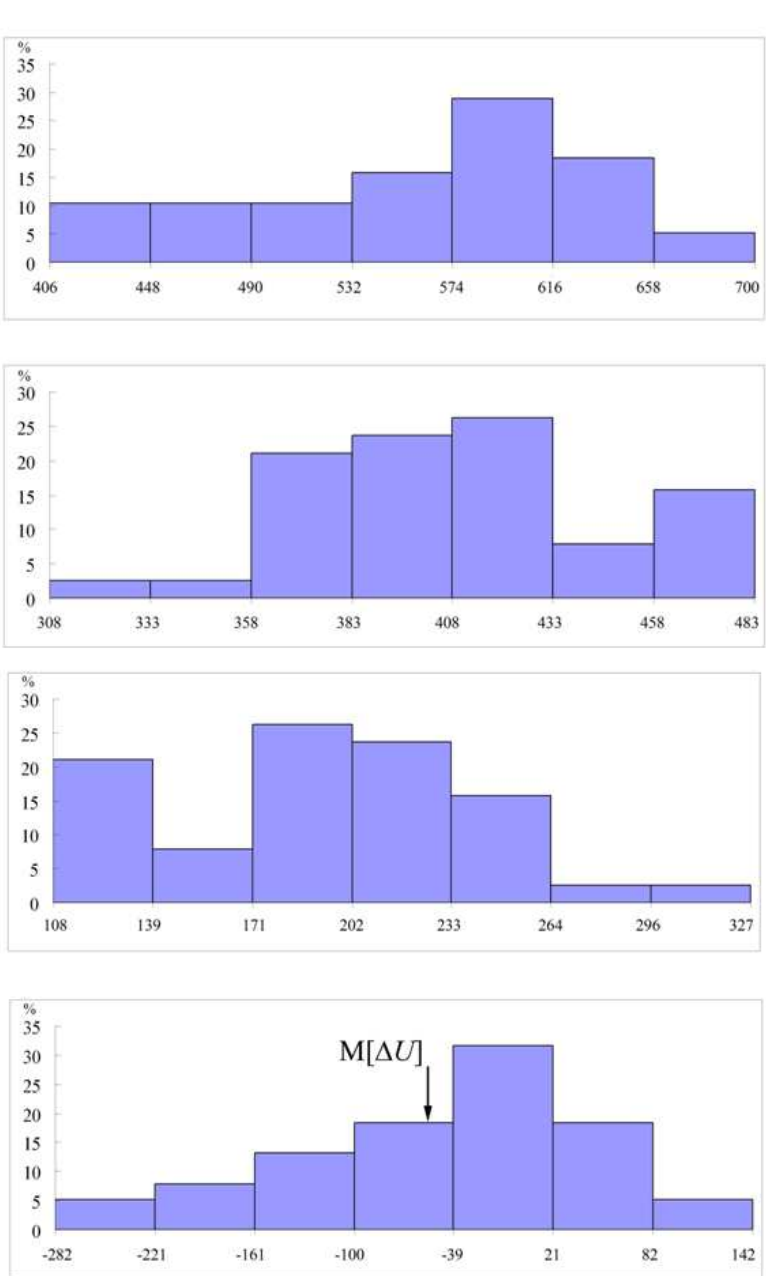

(a)

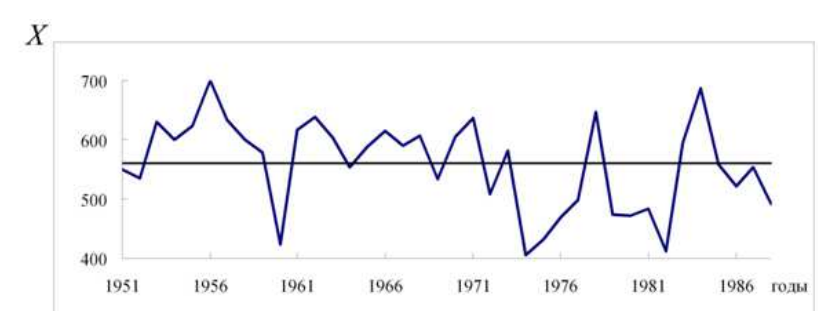

E

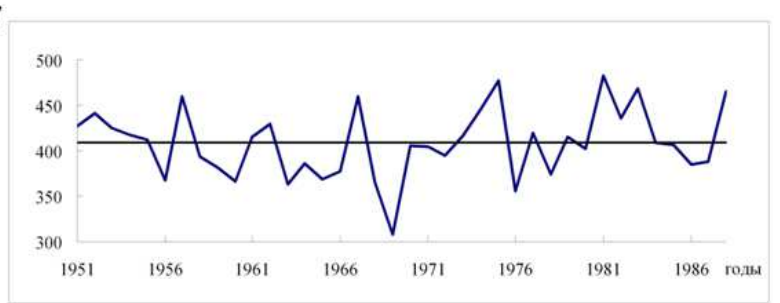

$Q$

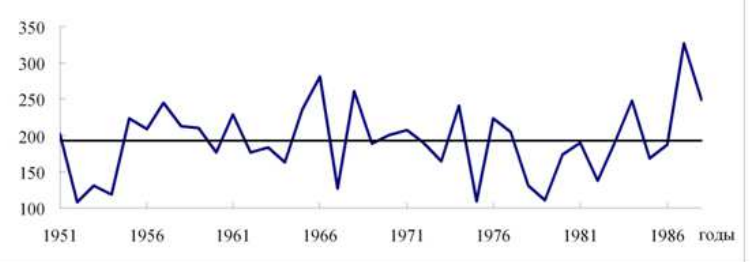

$\Delta U$

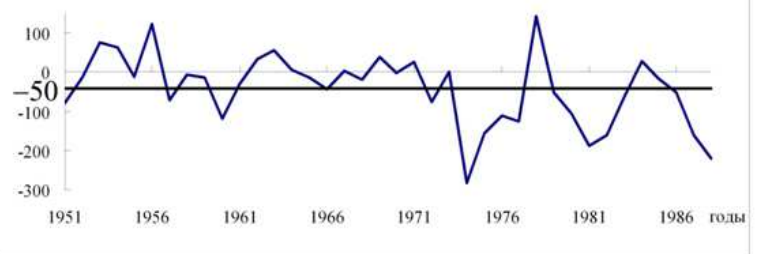

(b)

Fig. 3. Histogram (a) and chronological course of hydrometeorological elements, mm (b) (Cheptsa River - Polom settlement)

\section{Conclusion}

Thus, we discovered a previously unknown phenomenon of detection of long-term changes in water supply in soil of river basins, namely, that under nonzero interaction intensity of inflow (outflow) of moisture into a watershed and saturation (emptying) of soil, a nonzero value of the average annual values of water supply changes occurs, due to the systematic shift of the average value with respect to the mode of probability density distribution of water supplies.

One of the obvious applications of the discovered phenomenon is the adjustment of maps of the average long term evaporation in the areas, where the norm of water supply change is significantly different from zero.

\section{Acknowledgment}

This research was partly supported by the Ministry of education and science of the Russian Federation (Project № 1413 “Adaptation of mathematical models of formation probability characteristics of perennial species of river runoff to physiographic conditions in Russia for the purpose of ensuring the sustainability of their solutions for modeling and forecasting").

\section{Author's Contributions}

Viktor V. Kovalenko: Primarily responsible for idealistic and theoretical parts of the manuscript.

Ekaterina V. Gaidukova: Responsible for practical calculations in the manuscript.

\section{Ethics}

Lev N. Karlin was the rector of the organization in which the study was performed. George G. Ghoghoberidze organizes scientific work in the organization.

\section{References}

AL-Khlaifat, A.L., 2008. Dead sea rate of evaporation. Am. J. Applied Sci., 5: 934-942.

DOI: 10.3844/ajassp.2008.934.942 
Astapov, Y.M. and V.S. Medvedev, 1982. Statisticheskaya Teoriya System Avtomaticheskogo Regulirovaniya i Upravleniya. 1st Edn., Moscow, Nauka, pp: 304.

AMVB, 1974. Atlas mirovogo vodnogo balansa. Gidrometeoizdat, Leninrrad, Moscow,

Doganovsky, A.M. and V.G. Orlov, 2011. Collection of Problems in Identifying the Key Characteristics of Water Bodies of Land. 1st Edn., RSHU Publishers, St-Peterburg, ISBN-10: 978-5-86813-291-9, pp: 315.

Hosseini, M., M.S.M. Amin, A.M. Ghafouri and M.R. Tabatabaei, 2011. Application of soil and water assessment tools model for runoff estimation. Am. J. Applied Sci., 8: 486-494.

DOI: 10.3844/ajassp.2011.486.494

HP, 1981. Metody izucheniya i rascheta vodnogo balansa. Hydrometeorological publishing, Leningrad, pp: 398.

Konstantinov, A.R., 1968. Ispareniye v Prirode. 1st Edn., Hydrometeorological Publishing, Leningrad, pp: 532.
Kovalenko, V.V., 2009. Hydrological Maintenance of Reliability of the Building Projects at Change of a Climate. 1st Edn., RSHU Publishers, St-Peterburg, ISBN-10: 978-5-86813-234-6, pp: 100.

Kovalenko, V.V., 2012. Theoretical and experimental substantiation of the correlation between the fractal dimension of long-term flow series and the climatic norm of surface air temperature. Doklady Earth Sci., 444: 782-786. DOI: 10.1134/S1028334X12060232

Kovalenko, V.V. and E.V. Gaidukova, 2011. Influence of climatological norms of the surface air temperature on the fractal dimensionality of the series of longterm river discharge. Doklady Earth Sci., 439: 1183-1185. DOI: 10.1134/S1028334X1108023X

Rahnama, M.B. and G.A. Barani, 2005. Application of rainfall-runoff models to zard river catchments. Am. J. Environ. Sci., 1: 86-89.

DOI: 10.3844/ajessp.2005.86.89 